\begin{tabular}{llllll}
\hline & Age & Mean age & No. & PEPc & SD (PEPc) \\
\hline Group A & $1-20$ & 9.1 & 85 & 113.2 & 11.7 \\
Group B & $1-10$ & 6.0 & 52 & 110.3 & 9.04 \\
Controls & $3-10$ & 6.2 & 15 & 107.9 & 8.63 \\
IPVM & $3-10$ & 5.9 & 15 & 100.6 & 11.94 \\
\hline
\end{tabular}

IPVM-Innocent praecordial vibratory murmurs.

Using the two-tailed Student's t-test for independent samples the values of PEPc for the children with innocent praecordial vibratory murmurs are significantly different with respect to the PEPc value of group B $(P<0.01)$.
We concluded that children with innocent praecordial murmurs have a shorter PEP than children without one. Knowing this, a one-tailed Student ttest may be used to compare the controls and the innocent praecordial vibratory murmurs. The PEPc of the children with innocent praecordial vibratory murmurs is significantly shorter than matched controls $(P<0.05)$

Using a non-parametric method (Wilcoxon signed rank test) the same conclusion may be drawn.

G. M. A van der Hoeven and C. de Monchy, Institute of Medical Physics TNO, PO Box 5011, Utrecht, Holland.

\title{
Successful aortic valve replacement for aortic regurgitation associated with osteogenesis imperfecta
}

Sir:

The paper by Weisinger et al. (British Heart fournal, 1975, 37, 475) is similar to a published report by me (Pijoan de Beristain, 1973). This paper described a mother and son with aortic regurgitation associated with osteogenesis imperfecta. The mother died in 1960 but the son was operated on successfully in 1966 and is still alive and doing well. The surgeon's description of the aortic wall was similar to that of Weisinger et al. and also to that found in Marfan's disease.

I believe that in every case of isolated aortic regurgitation the stigmata of Marfan's syndrome and osteogenesis imperfecta must be looked for.

Carlos Pijoan de Beristain, Servicio de Cardiologia, Policlinica del Sagrado Corazon de Jesus, Barcelona-11, Spain.

\section{Reference}

Pijoan de Beristain, C. (1973). Association of aortic insufficiency with osteogenesis imperfecta in 2 members of the same family. Revista Española de Cardiologia, 26, 405. 